\title{
STUDIES ON BIOACTIVE POTENTIAL OF STREPTOMYCES SPP. (KX710212). ISOLATED FROM ENVIRONMENTAL POLLUTED SAMPLE, RANIPET, VELLORE, INDIA
}

\author{
HENITA GEO N, PANNEERSELVAM A*
}

Department of Zoology, Thiruvalluvar University, Serkadu, Vellore, Tamil Nadu, India. Email: selvampanneer772@gmail.com, sagoselvam@yahoo.co.in

Received: 19 August 2016, Revised and Accepted: 19 September 2016

\section{ABSTRACT}

Objective: Natural products from bacterial origin played and still play a valuable role in drug discovery and provide diverse health-promoting compounds that help to cure or alleviate serious diseases.

Methods: A total of 4 actinobacterial strains were isolated from 2 different environmental polluted soil samples collected from Ranipet, Vellore, Tamil Nadu, India. Of 15 isolates screened for antibacterial property, 4 isolates (PS1, PS2, and PS3) were found potent and characterized phenotypically and genotypically.

Results: The 16S rDNA gene sequences of potent strain showed 97\% similarity with Streptomyces spp. and termed as Streptomyces sp. The bioactivity was revealed by antibacterial and antioxidant activity.

Conclusion: Hence, these findings provide scientific evidence to validate the pharmacological use and have the potential contribution in the discovery of new lead that play a key role in the field of therapeutics.

Keywords: Actinomycetes, Bioactive compounds, Antibacterial property.

(C) 2016 The Authors. Published by Innovare Academic Sciences Pvt Ltd. This is an open access article under the CC BY license (http://creativecommons. org/licenses/by/4. 0/) DOI: http://dx.doi.org/10.22159/ajpcr.2016.v9s3.14788

\section{INTRODUCTION}

Microorganisms and especially bacteria are being examined as a source of novel antibiotics that are active against antibiotic resistant human pathogens [1,2]. It was rapidly found that actinomycetes were most frequently positive; in particular, nearly $50 \%$ of Streptomyces strains isolated were active, mainly against Gram-positive bacteria. This widely applied approach was very fruitful by the early 1960s, and members of all the main families of clinically useful antibiotics were discovered. With the exception of the penicillins, cephalosporins, and a few minor products, all were produced by actinomycetes. Their collective spectra of action covered, practically all the important bacterial pathogens. The Gram-positive, soil-dwelling bacteria of the order Actinomycetales, Streptomycetes exhibit an unusual, developmentally complex life cycle [3]. Moreover, the Streptomyces cell differentiation is typically accompanied by the production of secondary metabolites and is regulated by complex interrelated mechanisms [4]. To assess the potential of bioactive compounds isolated from new actinomycetes from environmental contaminated soil and to understand its mechanism underlying for its potency.

\section{METHODS}

\section{Samples collection and isolation}

Soil samples were collected from environmental polluted area of Ranipet, Vellore, Tamil Nadu. The soil were collected and were transported to laboratory and stored at $4{ }^{\circ} \mathrm{C}$ to isolate the microorganisms. Serially diluted soil were plated on starch casein agar incubated at room temperature for about 4 days.

Physiological, biochemical, and cultural characteristics The morphological and biochemical studies of actinomycetes were carried out using International Streptomyces Project. Growth on the media was compared with growth of the control and was recorded as negative or positive [5].

\section{$16 S$ ribosomal RNA amplification}

The 16S ribosomal RNA was amplified using the polymerase chain reaction (PCR) method with Taq DNA polymerase. PCR amplification was detected by agarose gel electrophoresis and was visualized by ultraviolet fluorescence after ethidium bromide staining. The sequence was compared for similarity with the reference species of bacteria contained in genomic database banks, using the NCBI BLAST available at http://www.ncbi-nlm-nih.gov/ [6].

\section{Phylogenetic analysis}

Phylogenetic and molecular evolutionary analyses were conducted using software included in MEGA version 3.0 package. The evolutionary history was inferred using the neighbor-joining method. The 16S rRNA sequence of the strains ERI-1, ERI-3, ERI-4, and ERI-26 were aligned using the Clustal W program against corresponding nucleotide sequences of representatives of the genus Streptomyces retrieved from GenBank. Phylogenetic tree was inferred by the neighbor-joining method. The bootstrap consensus tree inferred from 1000 replicates was taken to represent the evolutionary history of the taxa analyzed.

\section{Fermentation medium}

Fermentations were carried out for the potent isolate PS5 in production medium. At $200 \mathrm{rpm}, 30^{\circ} \mathrm{C}$ for 5 days, different culture conditions such as temperatures $\left(20,25,30,37\right.$, and $\left.45^{\circ} \mathrm{C}\right), \mathrm{pH}(6.0,6.5,7.0,7.5$, 8.0 , and 8.5), and incubation hours $(24,48,72,96,120$, and 144$)$ were studied to standardize the antibiotic production.

Liquid-liquid extraction

The 6 days grown culture broth was collected and filtered through Whatman No. 1 filter paper. The total culture filtrate $100 \mathrm{ml}$ was extracted using Ethyl acetate. The solvents were removed using simple distillation and vacuum rotary evaporator at $40^{\circ} \mathrm{C}$. The extracts were stored at $4^{\circ} \mathrm{C}$ until further use. Water extract was lyophilized and the concentrated metabolites were stored at $4^{\circ} \mathrm{C}$ until further use. 
Structure elucidation

Characterization and identification of the compound and the chemical bonds were carried out using Fourier transform-infrared (FT-IR). The FT-IR spectra of the purified compound were recorded using Thermo Nicolet, Avatar 370 spectrometer over the $4000-400^{\circ} \mathrm{cm}^{-1}$ range at the resolution of $4 \mathrm{~cm}^{-1}$.

\section{Antibacterial assay}

The antibacterial activity was determined by agar well diffusion assay. Various concentrations the crude extracts. The following test organisms were used for antibacterial studies. The selected microorganisms (Salmonella typhi [MTCC 441], Staphylococcus aureus [ATCC 25923]), (Escherichia coli [ATCC 25922], Pseudomonas aeruginosa [ATCC 27853]) were inoculated in $3 \mathrm{ml}$ of Mueller-Hinton Broth and incubated at $37^{\circ} \mathrm{C}$ for $24 \mathrm{hrs}$. After incubation period, the culture was diluted.

\section{Free radical scavenging activity}

The antioxidant activity was determined by 2, 2, Diphenyl-2-Picryl hydrazyl (DPPH) scavenging assay. Various concentrations (0.1, 0.5, 1.0, 3.0 , and $5.0 \mathrm{mg} / \mathrm{mL}$ ) of crude extracts were taken in separate tubes. Ascorbic acid was used as reference compound $(0.1,0.5,1.0,3.0$, and $5.0 \mathrm{mg} / \mathrm{mL}$ ). A freshly prepared solution of $0.002 \%$ DPPH in methanol was added to each tube containing different concentrations of extracts $(2 \mathrm{~mL})$. The samples were incubated in dark place at $37^{\circ} \mathrm{C}$ for 20 minutes and read at $515 \mathrm{~nm}$. Percentage inhibition of radical scavenging activity was calculated.

\section{Cell viability assay}

The 3-(4, 5-dimethylthiazol-2-yl)-2-5-diphenyl tetrazolium bromide), MTT assay, was incorporated to assess the viability of the cells $5 \times 10^{3}$ were seeded per well into 96 well plates. $100 \mu \mathrm{L}$ of the PS4 pure compound in triplicates with different concentrations ranging from $250,500,750$, and $1000 \mu \mathrm{g} / \mathrm{mL}$ was tested. $5 \mu \mathrm{g} / \mathrm{mL}$ of doxorubicin was used as internal positive control and $100 \mu \mathrm{L}$ of Dulbecco's modified Eagle medium was used as negative control and wells without any cells were considered as blank.

\section{RESULTS}

\section{Screening for potent actinobacterial strains}

In this study, the pharmaceutically useful actinomycetes were isolated from 2 different locations were selected at Ranipet, Vellore district, Tamil Nadu, India (Fig. 1). The samples were processed and isolated were characterized on starch casein agar. A number of 4 promising Streptomyces strains were identified, of which 1 strain was identified as novel.

The percentage frequency of the most common genera was determined as Streptomyces with 93\% occurrence soil samples tested. All the four potent actinomycetes isolates, which were evaluated for their antibacterial activity by cross streak assay, revealed 6 isolates with maximum activity (Fig. 2).

Further, the cross streak assay revealed the potent bioactive strains by the inhibiting pathogens. The isolate showed activity against Bacillus cereus $(2 \pm 0.05 \mathrm{~mm})$, S. aureus $(3 \pm 0.05 \mathrm{~mm})$, P. aeruginosa $(2 \pm 0.05 \mathrm{~mm})$, and $E$. coli $(1 \pm 0.05)$. Preliminary assay confirmed as the best isolate and it was further considered as the study organism. The cultures characteristics of all the potent four isolates were found aerobic, mesophilic, and grew readily on most of the nutrient media, which further showed round colonies with powdery texture. The morphological characterization of the strain was done based on the color of aerial and substrate mycelia which was identified with smooth surface. The strain was observed by the presence of spiral spores with smooth surface with gray-colored aerial mycelium. The frequent production of spreading substrate mycelia was observed, and the colonies were found darkened during sporulation with spirals. The colonies with powdery appearance had a characteristic feature with smooth surface. The ornamentation of spore surface of was observed under light microscopy and scanning electron microscope analysis ( 0.7 micron) (Figs. 3 and 4).

\section{Molecular characterization}

16S rDNA sequence of all the six potent isolates was submitted to GenBank. Clustering analysis for the six strains was found taxonomically very close to Streptomyces. Agarose electrophoresis revealed that

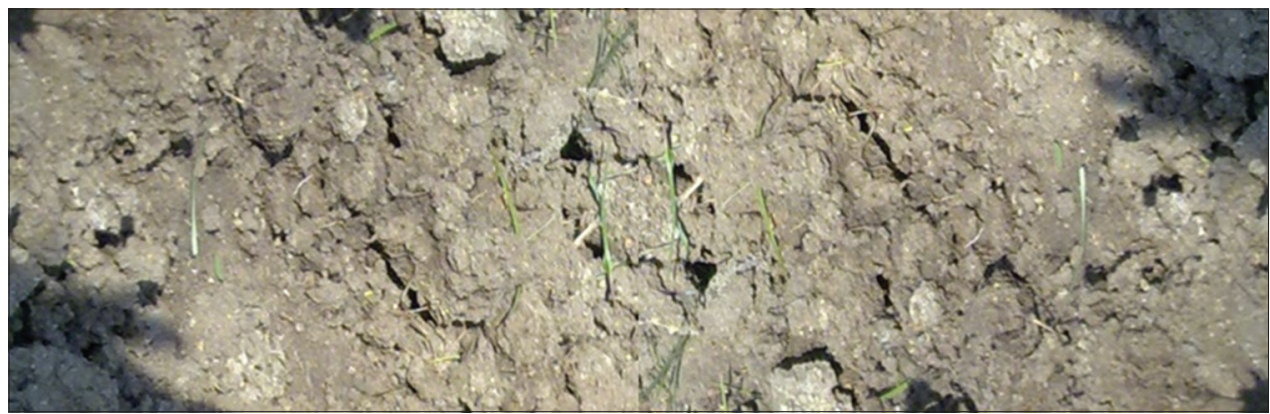

Fig. 1: Soil samples collected from Ranipet, Vellore district, Tamil Nadu, India
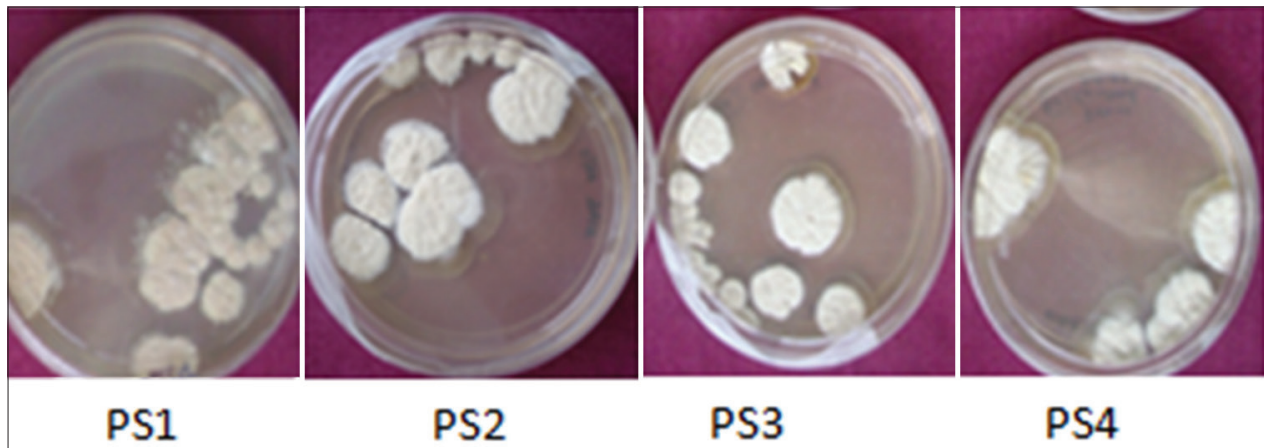

Fig. 2: Colony morphology of four potent actinomycetes isolated from soil samples 
the size of $16 \mathrm{~S}$ ribosomal RNA was around $>1.2 \mathrm{~Kb}$. Identification and phylogenetic affiliation of the new strain was determined and found similar to the family Streptomycetaceae belonging to genus Streptomyces. The $16 \mathrm{~S}$ rDNA gene sequences of strain PS4 showed 97\%

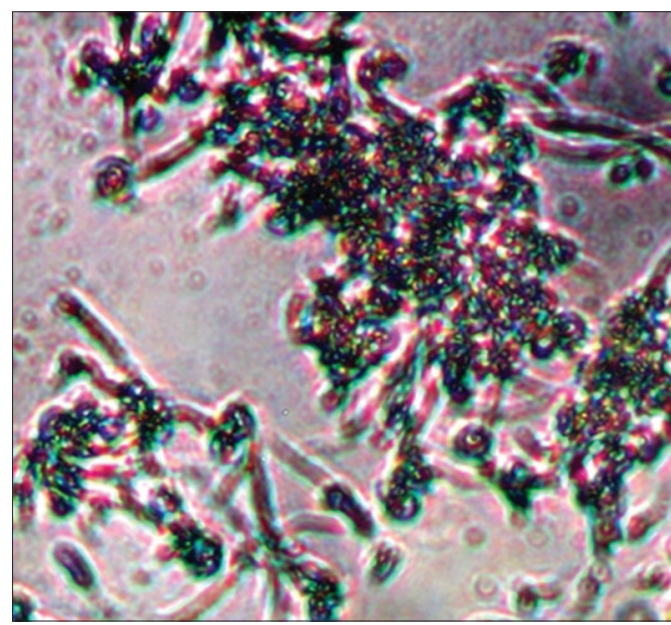

Fig. 3: Microscopic view of potent actinomycete isolates (Magnification, $\times \mathbf{1 0 0}$ )

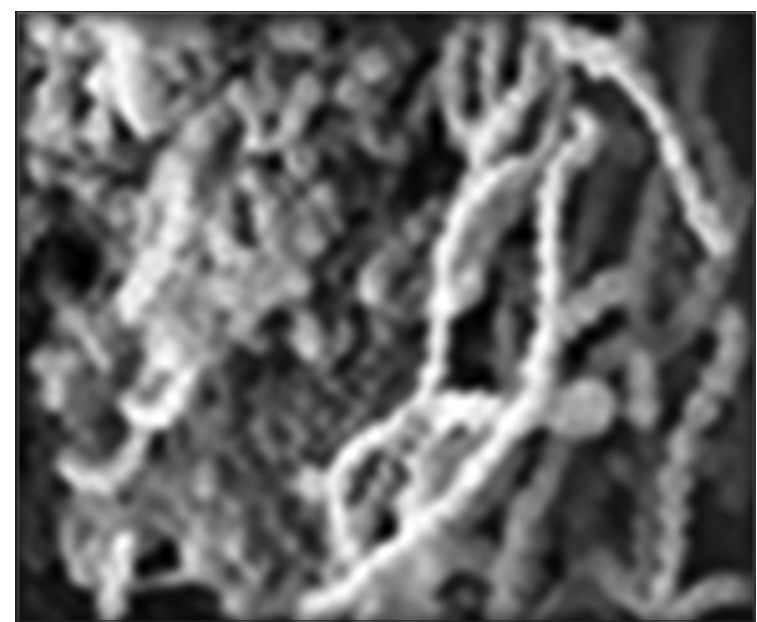

Fig. 4: Scanning electron microscope analysis of potent actinomycete isolates similarity with Streptomyces species, the most closely related species, further it was taxonomically assigned using the BLAST program of NCBI and the phylogenetic tree was constructed based on GeneBee software. The guanine-cytosine content of the strain was found to be $72.2 \%$. The unique combination of genotypic and phenotypic characterization allowed the parallel relatedness to its closest genotypic neighbors (Fig. 5). Hence, they represent a species of the genus Streptomyces, for which the name Streptomyces sp. PS4 is proposed, submitted to the GenBank database under the accession number.

\section{Extraction of secondary metabolites from six potent isolates}

The extraction of secondary metabolites was carried out for the potent isolate by liquid-liquid extraction methods. The bioactive metabolites from the shake flask cultures containing secondary metabolites were separated based on the enhancement of solvent specificity. In spite of using various solvent systems, maximum yield of metabolite and biomass was obtained from ethyl acetate extract. Different fermentation media were used as the base to determine the optimal nutritional conditions for the production of antimicrobial compounds. The influence of $\mathrm{pH}$ on the production of antimicrobial compounds revealed the maximum production with antibacterial activity for the strain Streptomyces sp. Among the different pH used, pH 7.0 exhibited good growth and antimicrobial activity against tested bacteria. Maximum cell growth was observed at $\mathrm{pH} 7.0$ and $\mathrm{pH} 7.5$ compared to other $\mathrm{pH}$. The effect of growth and antimicrobial metabolite production of strain Streptomyces sp. PS4 was analyzed at different temperatures. The temperature $27^{\circ} \mathrm{C}$ was found to be optimum for antimicrobial metabolite production and exhibited activity against all tested bacteria at different time intervals such as 24, 48, 72, and 96 hrs (Fig. 6). Ethyl acetate extract of the isolate Streptomyces sp. showed activity against bacterial pathogens. Alteration of sources resulted in a change of biological activity caused by variation in synthesis rate of bioactive compounds. The maximum activity was found utilizing starch as carbon source and beef extract as the nitrogen sources. The cultural conditions for the production of bioactive metabolites were found at $\mathrm{pH} 7.2$ and temperature $27^{\circ} \mathrm{C}$. The influence of rpm on the bioactive metabolite production was found higher at $200 \mathrm{rpm}$.

\section{Analysis}

The IR spectrum showed respective functional groups, which authenticates the characteristic compound. The IR spectrum of the compound showed $\alpha, \beta$ unsaturated carboxylic acid (Fig. 6).

\section{Bioactivity}

The antibacterial activity of the crude extracts from Streptomyces sp. exhibited maximum activity $P$. aeruginosa and $S$. aureus $(23 \mathrm{~mm} \pm 0.05)$ activity compared to the standard drug chloramphenicol (Fig. 7).



Fig. 5: Phylogenetic tree based on 16 S rDNA gene sequences of Streptomyces sp 
Antioxidant activity of potent isolate Streptomyces

The antioxidant potential of the crude extract tested at $(0.1,0.5,1.0$, 3.0 , and $5.0 \mathrm{mg} / \mathrm{mL}$ ) concentrations exhibited strong reducing power activity with $70 \pm 0.15 \%$ percent inhibition with the $\mathrm{IC}_{50}$ of $0.95 \mathrm{mg} / \mathrm{mL}$ (Fig. 8).

\section{DISCUSSION}

In the present study, Streptomyces strain was found to exhibit potential bioactivity. 518 Streptomyces strains and checked for their antibacterial and antifungal activities. It was found that $47.01 \%$ showed activity against $S$. aureus and $30 \%$ showed activity against E. coli. The majority of the isolates (46.43\%) showed combined antibacterial and antifungal activity and $25 \%$ showed only antibacterial activity. 280 actinomycetes were isolated from Kanyakumari district [5]. They showed good antibacterial and antifungal activity. Among the isolates, ERI-1, ERI-3, and ERI-26 showed significant activity against both Gram-positive and Gram-negative bacteria. These isolates were also exhibited good antifungal activity.

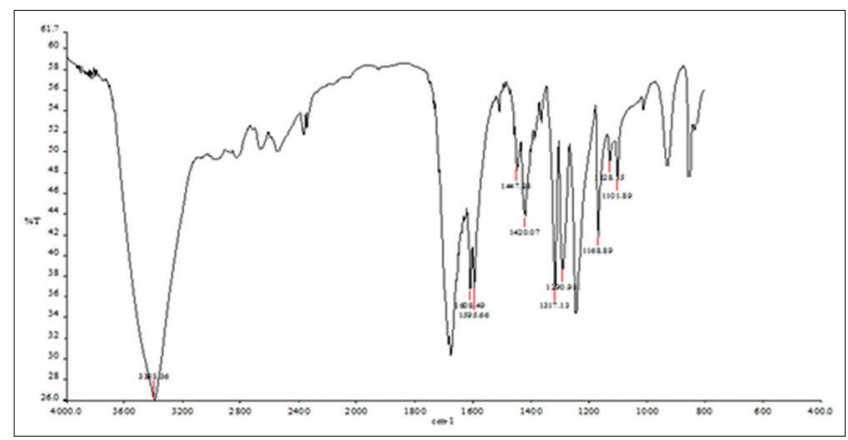

Fig. 6: Fourier transform infrared profile pattern of 3-benzylhexahydropyrrolo[1,2-A]pyrazine-1,4-dione

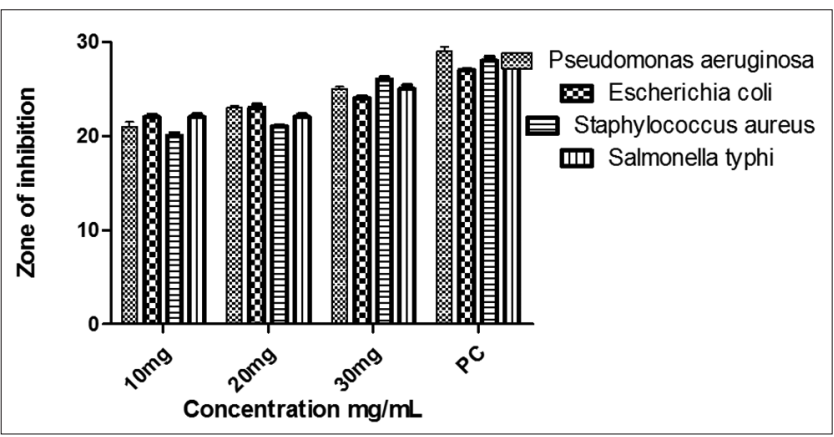

Fig. 7: Antibacterial activity of six potent strains against pathogens

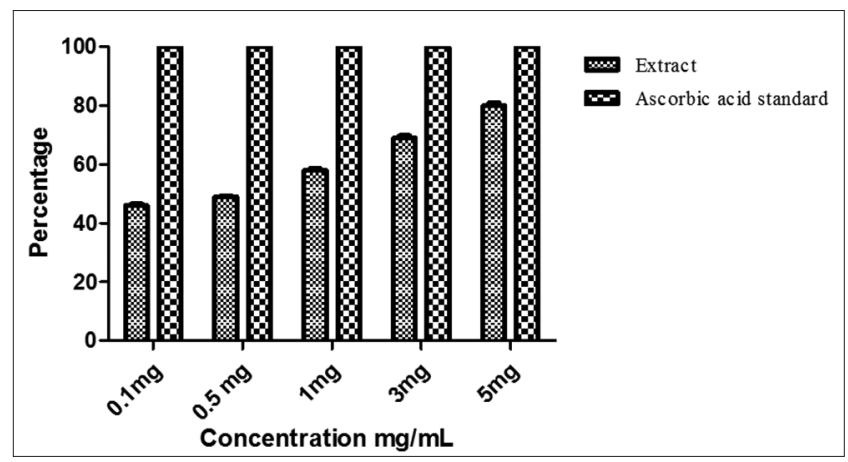

Fig. 8: Antioxidant activity
The compound from Streptomyces, p-hydroxybenzoic acid exhibited good activity against fungi. Trichophyton rubrum MTCC 296 and E. floccosum 73/01 showed MIC of $150 \mu \mathrm{g} / \mathrm{ml}$. Trichophyton simii 110/02, Curvularia lunata, Aspergillus niger, Botrytis cinerea, T. rubrum 57/01, Scropulariopsis sp., and Candida albicans exhibited minimum inhibitory concentration of $250 \mu \mathrm{g} / \mathrm{ml}$. Di-(2-ethyl hexyl)-phthalate from chloroform extract of actinomycetes and exhibited good activity against both Gram-positive and Gram-negative organisms at 128-256 $\mu \mathrm{g} \mathrm{ml}$. Quinone-anthracycline from Streptosporangium isolated from an Algerian soil, which exhibited activity against both Gram-positive and Gram-negative bacteria. Broadspectrum, an active compound isolated from Streptomyces sp. isolate number 419, showed good activity against wide range of Gram-positive and Gram-negative E. coli, Klebsiella pneumoniae, Micrococcus luteus, Proteus vulgaris, Providencia rettgeri, Proteus mirabilis, P. morganii, Pseudomonas fluorescens, Pseudomonas aeruginosa, and Pseudomonas syringae pv. syringae. Similarly, cytotoxicity studies and the apoptosis have been reported [7]. This study also provides an excellent basis for the investigation for a broad range of antimicrobial and anticancer activities [8-11]. With the above significant features, the strain could be recommended for its use in medicinal and agricultural sectors, an extensive knowledge on the behavior of natural compounds can be gained for the benefit of health [8-11].

\section{CONCLUSION}

The aim of this study was to explore the bioactive potential of Streptomyces sp. isolated from soil and understand the bioactive properties of the crude and the pure compounds. Hence, high mortality rates, serious side effects, deficiencies of the available chemotherapeutics, and high costs during treatment clearly underscore the need to develop new anticancer agents. With the above significant features, the strain could be recommended for its use in medicinal and agricultural sectors, an extensive knowledge on the behavior of natural compounds can be gained for the benefit of health.

\section{REFERENCES}

1. Choudury A, RahmanAbdur AA, Gafur AG. In vitro antibacterial and cytotoxic activities of a brown antibiotic metabolite from a strain of Actinomycetes. Science 2001;1(4):206-8.

2. Boudjella H, Bouti K, Zitouni A, Mathieu F, Lebrihi A, Sabaou N. Isolation and partial characterization of pigment-like antibiotics produced by a new strain of Streptosporangium isolated from an Algerian soil. J Appl Microbiol 2007;103(1):228-36.

3. Chater KF. Regulation of sporulation in Streptomyces coelicolor A3(2): A checkpoint multiplex? Curr Opin Microbiol 2001;4(6):667-73.

4. Hopwood DA. Forty years of genetics with Streptomyces: From in vivo through in vitro to in silico. Microbiology 1999;145 (Pt 9):2183-202

5. Laksmanaperumalsamy $P$, Chandramohan D, Natarajan R. Antibacterial and antifungal activity of Streptomycetes from Porto Novo coastal environment. Mar Biol 1978;11:15-24.

6. Maniatis T, Tritsch EF, Sambrook, J. Molecular cloning. In: A Laboratory Manual. $2^{\text {nd }}$ ed. New York: Cold Spring Harbor Laboratory, Cold Spring Harbor; 1989.

7. Sivasubramanian R. Brindha P. In vitro cytotoxic, antioxidant and GC-MS Studies on Centratherum punctatum. Int J Pharm Pharm Sci 2013;5(3):364-7.

8. Ilić SB, Sandra S. Konstantinović ZB. UV/VIS analysis and antimicrobial activity of Streptomyces isolates. Facta Univ Ser Med Boil 2005;2(1):44-6.

9. Wang Y. Zhang ZS. Ruan JS. Wang YM, Ali SM. Investigation of actinomycete diversity in the tropical rainforests of Singapore. J Ind Microbiol 1999;23:178-87.

10. Warth AD. Mechanism of action of benzoic acid on Zygosaccharomyces bailii: Effects on glycolytic metabolite levels, energy production, and intracellular pH. Appl Environ Microbiol 1991;57(12):3410-4.

11. Williams S.T., Cross T. Isolation, purification, cultivation and preservation of actinomycetes. Methods Microbiol 1971;4:295-333. 